\title{
Apomorphine Enhances Conditioned Responses Induced by Aversive Stimulation of the Inferior Colliculus
}

\author{
Ana Cristina Troncoso', Mario Yukio Osaki', Suely Mason', Karina G Borelli' and Marcus Lira Brandão*,' \\ 'Laboratório de Psicobiologia, Depto de Psicologia, FFCLRP, Ribeirão Preto, São Paulo, Brazil
}

\begin{abstract}
Consistent evidence has shown that learning may be produced in paradigms using electrical stimulation of the inferior colliculus (IC) as unconditioned stimulus (UCS). Recent reports have also demonstrated that aversive stimulation of the IC, at the escape threshold, enhances dopamine (DA) release in the prefrontal cortex. The purpose of the present study was to determine whether dopaminergic mechanisms are involved in the Pavlovian conditioning and latent inhibition using IC stimulation as UCS and light as conditioned stimulus (CS). Rats were placed inside a shuttle box and subjected to a two-way avoidance paradigm. IC aversive electrical stimulation was used as UCS and shuttle box illumination as CS. The rats quickly learned to avoid or interrupt the IC stimulation. Apomorphine injections produced a dose-dependent increase in the number of avoidance responses. On the other hand, chlorpromazine administration promoted a dose-dependent reduction of the avoidance responses. Previous injections of chlorpromazine inhibited the effects of apomorphine. Also, previous exposure to unreinforced light weakened the strength of the conditioning. Apomorphine blocked this latent inhibition effect, which was antagonized by previous injections of chlorpromazine. These findings bring evidence for the involvement of DA in the setting up of adaptive responses to aversive states generated at the IC level, which may underlie stressful situations present in anxiety.

Neuropsychopharmacology (2003) 28, 284-29I. doi:I 0. I 038/sj.npp. 1300034
\end{abstract}

Keywords: inferior colliculus; active avoidance; conditioned aversion; latent inhibition; dopamine; apomorphine

\section{INTRODUCTION}

The search for the subcortical organization of fear processing dates back to the beginning of the last century with seminal work by Bard (1929) indicating the hypothalamus as an important center of integration of defensive reactions. Two decades later, low mesencephalic levels were also implicated in these processes in a report with detailed observations of the behavior of chronically decerebrate cats, in which the full capabilities of hypothalamic animals were compared with those of mesencephalic and bulbospinal preparations (Bard and Match, 1951). An intriguing aspect on these studies was that the stimulus used on all occasions was a sound. The inferior colliculus (IC) is a midbrain tectum structure primarily involved in auditory information processing; it also integrates sensory information of aversive nature. Indeed, electrical or chemical stimulation of this structure induces responses such as freezing and flight responses that mimic fearful behavior elicited by environmental challenges (Schmitt et al, 1986; Brandão et al, 1988, 1994, 1999; Cardoso et al, 1994; Troncoso et al,

*Correspondence: Dr ML Brandão, Laboratório de Psicobiologia, Depto de Psicologia, FFCLRP, Campus da USP, Av. Bandeirantes, 3900, |4049-90|, Ribeirão Preto, São Paulo, Brazil, Tel: +55 16 63306/9, E-mail: mbrandao@usp.br

Received 9 August 200I; revised 19 March 2002; accepted 21 June 2002
1998; Castilho et al, 1999). Several studies have suggested modulatory roles for GABA, serotonin, opioids, excitatory amino acids and neuropeptides at the so-called brain aversion system, which includes the dorsal periaqueductal gray and IC (Brandão et al, 1982, 1994, 1999). The IC is connected to cortical areas (Adams, 1979; Hoffman and Ison, 1980; Meininger et al, 1986; Fuster, 1989; Hoffman Brodal, 1992). One of these pathways is provided by projections from the central nucleus of the IC to the prefrontal cortex through the medial geniculate nucleus, amygdala and dorsomedial thalamus (Fuster, 1989; Brodal, 1992). It has been shown that this circuit is concerned with the processing of auditory information of an aversive nature which triggers fear-like behaviors (Maisonnette et al, Hoffman 1996; Brandão et al, 1999).

It has been found that local application of the excitant amino acids, glutamate and NMDA, in the central nucleus of the IC resulted in increased acoustically evoked and spontaneous firing of most neurons of this region ( $\mathrm{Li}$ et al, 1998; Faingold et al, 1989). Recently, we have shown that like fear-evoking stimuli, apomorphine increases the magnitude of the evoked potential to loud sounds directly recorded from the central nucleus of the IC (Brandão et al, 2001; Sandner et al, 2002). Interestingly enough, aversive stimulation of this midbrain structure, at the escape threshold, enhances dopamine (DA) release in the prefrontal cortex (Cuadra et al, 2000). We believe that studies 
directed to the research of DA-mediated mechanisms of these processes have considerable relevance in the light of the changes at DA transmission that occur following external acute stressors (Fadda et al, 1978; Anisman et al, 1991; Biggio et al, 1990; Feenstra et al, 1995; Feenstra and Botterblom, 1996) and of the current knowledge that cortical DA projections are also activated by a wide variety of aversive stimulations (Thierry et al, 1976; Fadda et al, 1978; Deutch et al, 1985; Abercrombie et al, 1989; Feenstra and Botterblom, 1996; Goldstein et al, 1996).

Latent inhibition is the interference with associative learning by prior unreinforced exposures to a conditioned stimulus (Makintosh 1975; Lubow et al, 1982). Latent inhibition has been considered as a model for information filtering processesand demonstrates attentional processes in rats that are responsive to drug treatment in a fashion that parallels drug responses seen in humans with schizophrenia (Makintosh, 1975; Lubow et al, 1982; Dunn et al, 1993; Sandner et al, 2002). We have already shown that stimulation of neural circuits in the central nucleus of the IC supports Pavlovian conditioning and that latent inhibition may be demonstrated using stimulation of these neural circuits in the IC as negative reinforcement (Brandão et al, 1997; Troncoso et al, 1998; Castilho and Brandão, 2001).

As the IC - a primary acoustic structure of the brainstem-seems to have a functional link with other higher brain structures through dopaminergic mechanisms, the purpose of the present study was to detect dopaminergic activity in the IC and to determine whether DA mechanisms are involved in the Pavlovian conditioning and latent inhibition using IC stimulation as unconditioned stimulus (UCS). To this end, we used a two-way active avoidance procedure in which light was used as the warning signal (conditioned stimulus (CS)) for an electrical stimulation train applied to the IC. Electrical stimulation of the IC was then the UCS paired with the box illumination as a CS. For the latent inhibition procedure, unreinforced light stimuli were presented before the sessions. We examined the effects of systemic injections of the classical DA agonist apomorphine and the classical DA postsynaptic receptor antagonist chlorpromazine on these paradigms.

\section{MATERIALS AND METHODS}

\section{Animals}

A total of 92 male Wistar rats weighing 250-300 g were housed in individual Plexiglas-walled cages under a 12:12 dark/light cycle (lights on at 07:00 am) at $23 \pm 1^{\circ} \mathrm{C}$ and given free access to food and water throughout the experiment. The experiments reported in this article were performed in compliance with the recommendations of SBNeC (Brazilian Society of Neuroscience and Behavior), which are based on the US National Institutes of Health Guide for Care and Use of Laboratory Animals.

\section{Surgery}

The animals were anesthetized with tribromoethanol $(250 \mathrm{mg} / \mathrm{kg}$, i.p.) and fixed in a stereotaxic frame (David Kopf, USA). A brain electrode was implanted in the midbrain, aimed at the IC. The electrode was made of stainless-steel wire, $160 \mu \mathrm{m}$ in diameter, insulated except at the cross-section of the tip. The upper incisor bar was set at $3.3 \mathrm{~mm}$ below the interaural line, so that the skull was horizontal between bregma and lambda. The electrode was introduced vertically using the following coordinates, with the lambda serving as the reference for each plane: posteroanterior, $1.2 \mathrm{~mm}$; medio-lateral, $1.5 \mathrm{~mm}$; dorso-ventral, $4.5 \mathrm{~mm}$ (Paxinos and Watson, 1997). The electrode was fixed to the skull by means of acrylic resin and three stainless-steel screws. The electrode wire was connected to a connector so that it could be plugged into an amphenol socket at the end of a flexible electrical cable used for brain stimulation.

\section{Apparatus}

One week after surgery, the rats were placed in an open field - a circular enclosure $60 \mathrm{~cm}$ in diameter and $50 \mathrm{~cm}$ high. The rats were allowed a $15 \mathrm{~min}$ period of habituation in the enclosure. The brain was stimulated electrically by means of a sine wave stimulator (Marseillan, 1977). The stimulation current was monitored by measuring the voltage drop across a $1 \mathrm{k} \Omega$ resistor with an oscilloscope (Labo, Brazil). Brain stimulation (AC, $60 \mathrm{~Hz}, 15 \mathrm{~s}$ ) was presented at $1 \mathrm{~min}$ intervals with the current intensity increasing by steps of $1.4 \mu \mathrm{A}$ (rms) for measurements of the escape threshold. Escape threshold was operationally defined as the lowest current intensity that produced running or jumping in two successive ascending series of electrical stimulation. Animals with an escape threshold above $70 \mu \mathrm{A}$ (rms) were discarded from the experiment.

The active avoidance cage consisted of a shuttle box comprising two compartments $30 \times 25 \times 25 \mathrm{~cm}$ with a $2.5 \mathrm{~cm}$ high barrier between them, and was equipped with 4 photoelectrical cells equally spaced on the back wall. This arrangement allowed one to detect the shuttle locomotion of the rat as well as its gross locomotor activity within each compartment. The grid floor consisted of bars spaced $1.2 \mathrm{~cm}$ apart. A $28 \mathrm{~V}$ light bulb was centered on the rear wall of each compartment of the chamber, $12 \mathrm{~cm}$ from the floor. The light was turned on and off noiselessly. The IC stimulation was delivered by a protected wire lead that entered the conditioning chamber through a $2 \mathrm{~cm}$ hole located in the top wall of the chamber. The rat was placed in the shuttle box and had its brain electrode connected to a flexible wire cable, allowing ample movement inside the box. The cable, in turn, was connected to the stimulator by means of a mercury swivel mounted on the top of the experimental chamber. The brain stimulation was applied at a current intensity $5 \%$ below the escape threshold previously determined in the open field. The adequacy of this current intensity level for the escape response was verified on the basis of a previous study from this laboratory (Melo et al, 1992; Brandão et al, 1997; Troncoso et al, 1998).

\section{Procedure}

After the determination of the aversive threshold, the animals were placed inside the shuttle box ( $10 \mathrm{~lx}$ at the floor level) and left for $15 \mathrm{~min}$ for habituation to the experimental context before the beginning of the session. The animals 
were randomly assigned to five groups, which received one of the following treatments: (a) $0.5 \mathrm{mg} / \mathrm{kg}$ of apomorphine, $n=9$; (b) $2.0 \mathrm{mg} / \mathrm{kg}$ of apomorphine, $n=9$; (c) $1.0 \mathrm{mg} / \mathrm{kg}$ of chlorpromazine, $n=8$; (d) $2.0 \mathrm{mg} / \mathrm{kg}$ of chlorpromazine, $n=8$. The fifth group served as the control group and received i.p. injections of the vehicle $(n=8)$. All injections were given $30 \mathrm{~min}$ before the sessions. After these groups were tested, an additional group of animals $(n=8)$ was included in which $0.5 \mathrm{mg} / \mathrm{kg}$ of apomorphine was challenged with $2.0 \mathrm{mg} / \mathrm{kg}$ of chlorpromazine. The animals were submitted to a session that consisted of 50 trials. Two successive trials were separated by a random interval from 10 to $50 \mathrm{~s}$. Each animal was submitted to only one session. During each conditioning trial, the shuttle box was illuminated for $20 \mathrm{~s}$ ( $100 \mathrm{~lx}$ at the floor level) followed by an electrical stimulation $(\mathrm{AC}, 60 \mathrm{~Hz}, 10 \mathrm{~s})$ applied through the implanted electrode. Whenever a rat passed from one compartment to the other during the illumination, it avoided the brain stimulation (avoidance responses = latency below $20 \mathrm{~s}$ ); if it changed compartments during electrical stimulation of the brain, then the stimulation was automatically terminated (escape responses = latency between 20 and $30 \mathrm{~s}$ ). The latencies and the number of avoidance and escape responses were individually recorded as well as the intertrial locomotor activity.

For the latent inhibition experiments, the two-way avoidance session also consisted of 50 trials. Each animal received 50 pre-exposures to the CS (light) in the shuttle box before the session, instead of experiencing the period of habituation of the conditioning experiment. The animals were divided into four groups that were allocated to the following drug treatments: (a) vehicle (saline, control group), $n=8$; (b) $0.5 \mathrm{mg} / \mathrm{kg}$ of apomorphine, $n=8$; (c) $2.0 \mathrm{mg} / \mathrm{kg}$ of chlorpromazine, $n=8$; (d) chlorpromazine $(2.0 \mathrm{mg} / \mathrm{kg})+$ apomorphine $(0.5 \mathrm{mg} / \mathrm{kg}), \quad n=8$. In these experiments drugs were injected immediately before the sessions.

The presentation and termination of the conditioned and unconditioned stimuli, along with all data collection, were controlled by a PC computer connected through an interface to the experimental chamber.

\section{Drugs}

Apomorphine hydrochloride 0.5 . and $2.0 \mathrm{mg} / \mathrm{kg}$ (Sigma, USA) and chlorpromazine hydrochloride 1.0 and $2.0 \mathrm{mg} / \mathrm{kg}$ (Sigma, USA) were each dissolved in physiological saline $(0.9 \%)$ shortly before use. Doses and waiting time for drug effects were chosen on the basis of the peak of effects of these DA agents observed in a preliminary study of this laboratory (Furlan and Brandão, 2001). The doses of the drugs were administered in a constant volume of $1 \mathrm{ml} / \mathrm{kg}$, i.p.

\section{Histology}

Upon completion of the experiments, the animals were deeply anesthetized with sodium pentobarbital and perfused intracardially with saline followed by formalin solution (10\%). Three days later the brains were removed and frozen. Serial $50 \mu \mathrm{m}$ brain sections were cut using a microtome and stained with Evans blue (2\%) in order to localize the positions of the electrode tips according to the Paxinos and Watson atlas (1997).

\section{Monoamine Assays}

The animals $(n=10)$ were killed by decapitation, the brain was quickly removed and the central nucleus of the IC of both sides was punched out, weighed and kept at $-80^{\circ}$ until DA and 3,4-dihydroxyphenylacetic acid (DOPAC) were measured by high-pressure liquid chromatography (HPLC). The HPLC system was equipped with a reverse-phase column (Shim Pack CLC-OSD (M) $25 \mathrm{~cm}, 5 \mu \mathrm{m}$ and $100 \AA$ pore diameter particle size; Shimadzu, Kyoto, Japan), coupled with electrochemical detection. The samples were homogenized in percloric acid $0.2 \mathrm{M}$, centrifuged at $15000 \mathrm{rpm}$ during $20 \mathrm{~min}$, at $-6^{\circ} \mathrm{C}$, and $20 \mu \mathrm{l}$ were injected into the HPLC-EC system. The HPLC system consisted of a Shimadzu chromatograph LC-10 AD, with a communication bus module CBM-10A, an on-line degassing unit DGU-14A, an L-ECD - 6A electrochemical detector with a glass-carbon electrode and a pump LC-10 AD. The potential was set at $850 \mathrm{mV}$ ( $v s$ a $\mathrm{Ag} / \mathrm{AgCl}$ reference electrode). The mobile phase containing $149 \mathrm{mM}$ citric acid, $10 \mathrm{mM}$ of $\mathrm{NaCl}, 800 \mathrm{ml}$ of distilled water, 1-octane sulfonic acid, $48 \mathrm{ml}$ of acetylnitrile and $28 \mathrm{ml}$ of tetrahydrofurane, $(\mathrm{pH} \mathrm{3.0)}$ was filtered and pumped through the system at a flow rate of $1.0 \mathrm{ml} / \mathrm{min}$. Quantification of all substances was made by comparing the peak area to a standard.

\section{Analysis of Results}

Data are reported as mean \pm SEM. Latencies for avoidance and frequency of avoidance responses obtained in the conditioning experiments were subjected to a two-way analysis of variance (ANOVA) with repeated measures using the drug condition as a between factor and blocks as the repeated measure factor. For the latent inhibition experiment, one-way ANOVA was used to analyze both frequencies and latencies of responses in the entire session. Post hoc differences between group means were tested with the Newman-Keuls test. A $P$ lower than 0.05 was considered significant.

The DOPAC/DA ratio was used to calculate the dopaminergic activity in the IC. Comparison of the data of DA, DOPAC and dopaminergic activities was done by Student's $t$-test. A $P$ value of $<5 \%$ was considered significant.

\section{RESULTS}

The tips of the electrodes were situated inside the central nucleus of the IC as shown in Figure 1. Gradual increases in the current intensity induced alertness, freezing and escape reactions expressed by running and/or jumping accompanied by piloerection, defecation and micturition. No audible vocalizations could be detected during the stimulation of the IC of the animals used in this study. The intensity of the electric current applied to the IC of the animals to induce escape responses was $54.12 \pm 6.25 \mu \mathrm{A}$ (rms).

Figure 2a presents the mean frequency of avoidance responses of the six groups across the sessions blocks. Significant differences emerged between treatments: drug effects $\mathrm{F}(5,176)=10.28, P<0.001$. Overall, the number of 


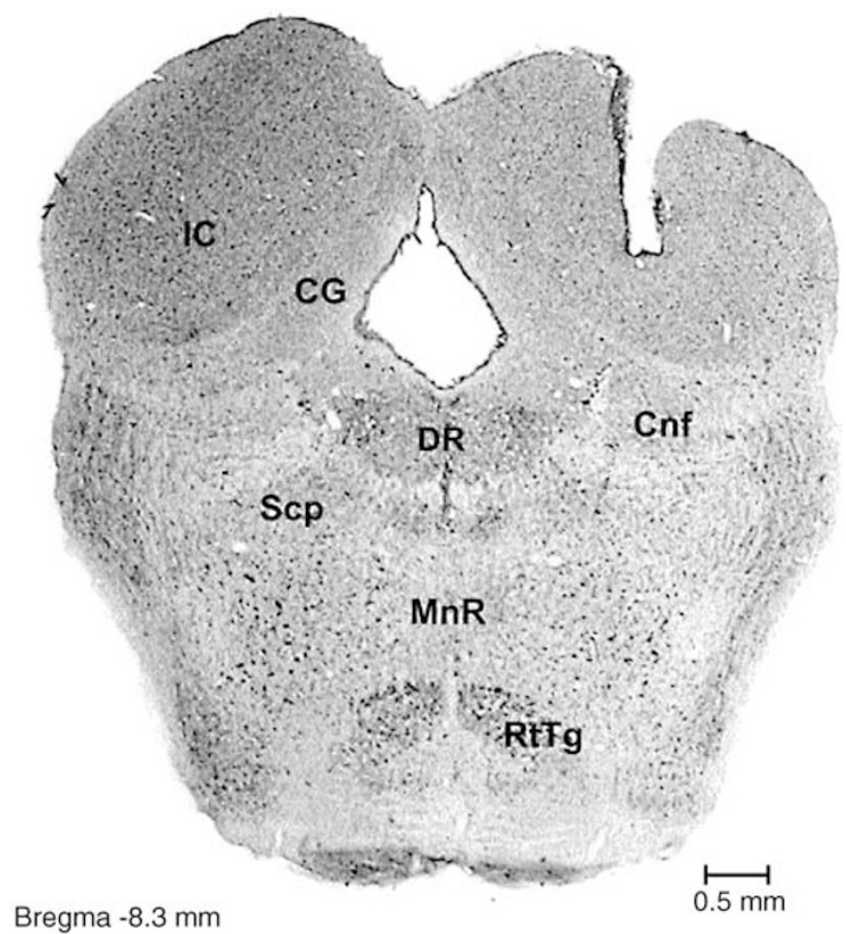

Figure I Photomicrograph showing a typical example of an electrode implanted in the central nucleus of the IC. IC: inferior colliculus; DR: dorsal raphe nucleus; SCP: superior cerebellar peduncle; RtTg: reticulopontine tegmental nucleus; Cnf: cuneiform nucleus; CG: central gray; MnR: median raphe nucleus. Bar $=500 \mu \mathrm{m}$.

avoidance responses significantly increased across blocks of 10 trials: block effect, $\mathrm{F}(4,176)=13.34, P<0.001$. These changes across blocks, however, did not vary as a function of drug treatment: treatment $\times$ blocks interaction, $\mathrm{F}(20$, $176)=0.27, P>0.05$. Inspection of Figure $2 \mathrm{a}$ indicates that control rats showed increased avoidance responses across blocks. Figure $2 \mathrm{~b}$ presents the latencies for avoidance responses of the six groups in the whole session. As can be seen, these measures were also significantly changed by treatments, $\mathrm{F}(5,44)=12.17, P<0.01$. Post hoc the NewmanKeuls method showed that the significant effects were caused by differences between the treatment with apomorphine $(0.5 \mathrm{mg} / \mathrm{kg})$ and chlorpromazine $(1$ and $2 \mathrm{mg} / \mathrm{kg})$ in relation to the control group. Here also, previous injections of chlorpromazine $2 \mathrm{mg} / \mathrm{kg}$ inhibited the effects of apomorphine $0.5 \mathrm{mg} / \mathrm{kg}$. The enhancement of the acquisition of the conditioned responses caused by apomorphine $0.5 \mathrm{mg} / \mathrm{kg}$ was clearly reduced by previous injection of chlorpromazine. The analyses are consistent with the assertion that dopaminergic agonists strengthen the acquisition of conditioned responses and that classical antipsychotic agents as chlorpromazine reduce the avoidance responses to aversive stimulation. These data are shown in Figure $2 b$.

Analysis of the intertrial locomotor activity (crossings) during the conditioning sessions did not reveal any particular drug effects on the motor performance of the animals $(\mathrm{F} 5,44=1.63, P>005)$. In general, escape responses always occurred when the animals did not respond over the 20-s period of light CS. The latencies of escape responses did not change across treatment groups $(\mathrm{F}(5$, 44) $=1.84, P>0.05)$.
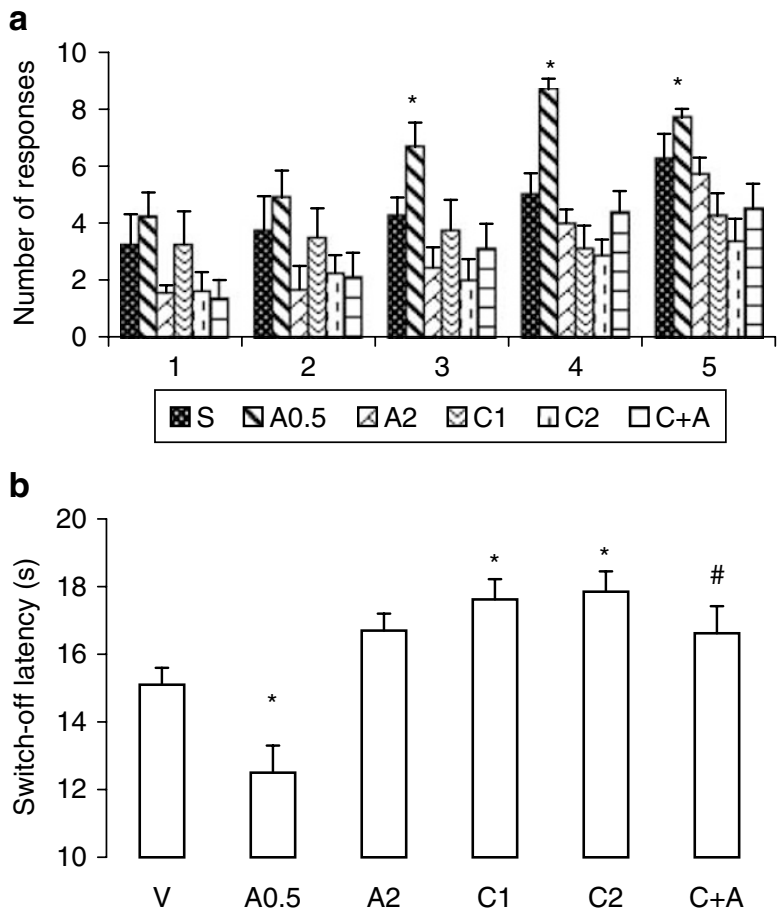

Figure 2 (a) Mean ( \pm SEM) of avoidance responses across blocks of 10 trials during sessions with six groups of rats injected with saline, 0.5 and $2.0 \mathrm{mg} / \mathrm{kg}$ of apomorphine, 1.0 and $2.0 \mathrm{mg} / \mathrm{kg}$ of chlorpromazine and chlorpromazine $(2.0 \mathrm{mg} / \mathrm{kg})$ +apomorphine $(0.5 \mathrm{mg} / \mathrm{kg})$, and submitted to 50 trials of conditioning with pairing electrical stimulation of the IC with neutral conditioned stimulus (box illumination). (b) Latencies of avoidance responses in the same experimental situation. Drugs were injected $30 \mathrm{~min}$ before the sessions. $* P<0.05$ in relation to the control group injected with saline and $\# P<0.05$ in relation to the group injected with apomorphine $0.5 \mathrm{mg} / \mathrm{kg}$, Newman-Keuls comparisons. S, saline; A, apomorphine; C, chlorpromazine. $N=8$ for saline, I and $2 \mathrm{mg} / \mathrm{kg}$ of chlorpromazine, $N=9$ for apomorphine 0.5 and $2.0 \mathrm{mg} / \mathrm{kg}$ and $\mathrm{N}=8$ for the chlorpromazine+ apomorphine group.

ANOVA performed on the data obtained with latent inhibition experiments revealed significant effects of drug injections upon the number $(\mathrm{F}(4,39)=6.92, P<0.001)$ and latencies $(\mathrm{F}(4,39)=6.07, P<0.001)$ of avoidance responses. Newman-Keuls test showed that the pre-exposure group injected with saline showed a significant reduction in the avoidance behavior, while apomorphine injections $(0.5 \mathrm{mg} /$ $\mathrm{kg}$ ) caused a significant increase in this behavior. The effects of apomorphine were clearly inhibited by a previous injection of chlorpromazine $1 \mathrm{mg} / \mathrm{kg}$. The effects of chlorpromazine on its own on these measures were not different from the saline pre-exposed group. These data are depicted in Figure 3.

Table 1 shows the data of the neurochemical assays comparing the DA activity in the left and right IC. There were no differences $(\mathrm{df}=18)$ in the levels of DA $(t=0.84$, $P>0.05)$, DOPAC $(t=0.99, P>0.05)$ and the DOPAC/DA ratio $(t=1.54, P>0.05)$ in both central nuclei of the IC.

\section{DISCUSSION}

All stimulated sites producing defensive behavior in the present study were situated in the ventral aspect of the 


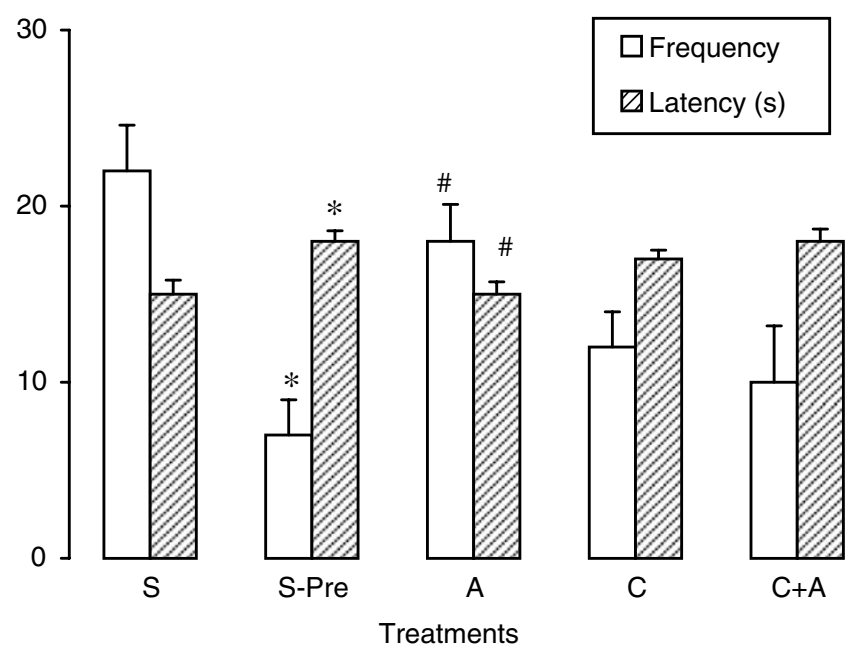

Figure 3 Effects of apomorphine $(0.5 \mathrm{mg} / \mathrm{kg}$, i.p.) on the latent inhibition caused by 50 light pre-exposures before the session of two-way avoidance (mean $\pm \mathrm{SEM})$. Each animal was injected with saline or apomorphine immediately before the sessions in the pre-exposed groups. Apomorphine was injected soon after chlorpromazine in the group $\mathrm{C}+\mathrm{A}$. Open columns: number of avoidance responses. Hatched columns: latencies for avoidance responses. * different from the non pre-exposed group injected with saline and \# different from the pre-exposed group treated with saline (NewmanKeuls test, $P<0.05)$. S, saline; $A$, apomorphine; $C$, chlorpromazine $(2.0 \mathrm{mg} /$ $\mathrm{kg}) . N=8$ for each group.

Table I Levels in ng/g of Brain Tissue and Metabolite-toTransmitter Ratios (means \pm SEM) in the Left and Right $\mathrm{IC}^{\prime}$

\begin{tabular}{llll}
\hline & DA & DOPAC & Ratio \\
\hline IC left & $79.02 \pm 6.54$ & $50.25 \pm 5.98$ & $0.63 \pm 0.08$ \\
IC right & $84.30 \pm 5.32$ & $44.30 \pm 4.74$ & $0.53 \pm 0.07$ \\
\hline
\end{tabular}

No differences between the left and right IC could be detected in all cases. $P>0.05$, paired t-test. $N=10$. 'DA, dopamine, DOPAC, 3,4-dihydroxyphenylacetic acid.

central nucleus of the IC, a region traditionally known to process high-pitched sounds (Rose et al, 1963; Merzenich and Reid, 1974). The present results show that rats quickly learn to make a shuttling response in order to avoid or escape from the electrical stimulation of the IC. This represents a consistent demonstration of learning using aversive states induced by IC stimulation as UCS and light stimulation as CS. The rats increased their rate of responding in the presence of the CS (cage illumination) over number of trials. The pattern of results obtained in the present experiments parallels those from typical avoidanceescape procedures, which utilize electric shock as the UCS, for example, an auditory stimulus paired with foot shock elicits classical conditioned responses (LeDoux et al, 1986, 1990). From the anatomo-functional viewpoint, the IC may be associated with the processing of aversive conditioned stimuli and, for extension, with conditioned fear (Brandão et al, 2001; Castilho and Brandão, 2001). Therefore, the present results are in line with recent evidence obtained in this laboratory that has shown that rats learn to avoid the IC stimulation when the warning stimulus is a light and not a tone (Troncoso et al, 1998).
In accordance with several studies (Brandão et al, 1994, 1999), the present results show that escape behavior is normally obtained with gradual increases in the intensity of electrical stimulation of the IC. The fear-like nature of this stimulation has been previously shown in this laboratory, as rats submitted to avoidance paradigms avoid and quickly learn to switch off such stimulation in the IC (Melo et al, 1992; Troncoso et al, 1998). Nevertheless, we cannot discard the current spreading to neighboring structures such as dorsal periaqueductal gray or cuneiform nucleus, other structures whose stimulation is known to cause defensive behaviors (Amano et al, 1978; Nashold et al, 1969; Bandler et al, 1985; Redgrave et al, 1988; Dean et al, 1988; Mitchell et al, 1988; Graeff, 1994). We predict the existence of neural substrates for defensive behavior in the IC, not only because of the aversive properties of its electrical stimulation but mainly because chemical stimulation with bicuculline or excitatory amino acids such as NMDA and glutamate causes similar aversive responses (Brandão et al, 1999, Pandossio et al, 1999). Moreover, systemic or local injections of GABA agonists or benzodiazepines into this midbrain structure promptly reduce the aversive consequences of their electrical stimulation (Melo et al, 1992; Pandossio and Brandão, 1999). As GABA receptor antagonists mimic the effects of the electrical stimulation, it has been suggested that the neural substrate of aversion in this midbrain region be under GABAergic tonic inhibitory modulation (Melo et al, 1992; Brandão et al, 1988, 1993, 1994, 1997). Local injections of serotonergic agents known for their antiaversive action when injected in other structures of the brain aversion system also decrease the aversiveness of the exposure of rats to the elevated plus-maze test (Melo and Brandao, 1995).

Based on evidence from this and other laboratories, we have proposed that the IC contributes to some basic link between auditory inputs of aversive nature, and the generation and elaboration of defensive behavior in response to threat or danger (see Brandão et al (1999) for a review on this topic). Furthermore, we have shown that electrical stimulation of the IC of rats in intensity sufficient to induce escape behavior enhances subsequent fear-like behaviors when behaviorally tested in the elevated plusmaze test (Pandossio et al, 2000).

Apomorphine $0.5 \mathrm{mg} / \mathrm{kg}$ clearly enhanced the aversive effects caused by electrical stimulation of the IC, while $2.0 \mathrm{mg} / \mathrm{kg}$ did not produce changes in the aversiveness of this stimulation. Activation of dopaminergic receptors by this dopaminergic agent seems to account for this behavioral sensitization as chlorpromazine $2.0 \mathrm{mg} / \mathrm{kg}$, a dose that did not cause apparent change in the animal motor activity, significantly counteracted the effects of apomorphine. Besides, the observed effects of these dopaminergic drugs cannot be attributed to nonspecific effects, as they did not affect the intertrial motor activity or the escape latencies of the animals in the two-way avoidance procedure. The differential effects of the two doses of apomorphine in the present study is consonant with several other studies that report either an increase or a decrease in receptor sensitivity with low and high doses of apomorphine, respectively. To determine a reason for these differential effects of systemically administered apomorphine has been a complicated matter because the drug acts 
on several DA pathways, as it acts differentially at different DA subtypes. For example, apomorphine has been reported to be a full agonist at D2 receptor sites (Creese et al, 1983). Moreover, although D2 receptors are found both pre- and postsynaptically, it has been reported that the presynaptic sites are between 6 and 10 times more sensitive to apomorphine than the postsynaptic sites (Skirboll et al, 1979). As expected, chlorpromazine produced a dosedependent reduction in animal reactivity to the aversive stimulation of the IC. A local action of apomorphine in the IC cannot be discarded, as appreciable dopaminergic activity exists therein as shown by the present study and also because this drug enhances the auditory-evoked potentials directly recorded from the central nucleus of this midbrain region (Sandner et al, 2002). Strong support to our neurochemical data showing significant concentrations of DA in the IC is provided by a recent paper that demonstrate the presence of mRNA for D2 but not D1receptors in human IC (Hurdy et al, 2001). Besides, substantia nigra does not seem necessary for this dopaminergic activity as recent evidence has shown that lesions of this structure, pars compacta included, did not affect the DA levels in the IC (Maisonnette et al, 1998). Further studies using systemic and local injections into the IC of selective D1- and D2-receptor antagonists on apomorphine's enhancement of learning will help to elucidate this point.

The association of changes in dopaminergic transmission and threatening challenges has already been demonstrated by numerous reports. In fact, alterations of DA transmission always occur following the exposure to a wide variety of acute stressors (Anisman et al, 1991) and cortical DA projections are also activated by diverse types of aversive stimulation (Thierry et al, 1976; Fadda et al, 1978; Anisman et al, 1991; Feenstra et al, 1995; Feenstra and Botterblom, 1996; Goldstein et al, 1996). Although the precise neural circuit of the DA transmission involved in aversive states remains unclear, pharmacological and neurochemical studies seem to point to DA prefrontal neurons (Espejo and Miñano, 1999; Morrow et al, 1999). Support for a functional link between the activation of DA prefrontal neurons and the behavioral responses induced by IC aversive stimulation has been reported recently (Cuadra et al, 2000). Although there are substantial cortical inputs to dorsal midbrain regions, it is established that the IC also projects densely to cortical areas, mainly to the temporal lobe (Cooper and Young, 1976; Fadda et al, 1978; Adams, 1979; Meininger et al, 1986). In fact, the IC is a key pathway for auditory information and disturbances at this level may alter the transmission to cortical centers. An indirect pathway connecting these structures is given by projections from the central nucleus of the IC-medial geniculate nucleusamygdala-dorsomedial thalamus-prefrontal cortex (Fuster, 1989; Brodal, 1992; Cardoso et al, 1994). It has been shown that this alternate circuit is concerned with the processing of auditory information of aversive nature, which triggers fear-like behaviors (LeDoux et al, 1990; Maisonnette et al, 1996). Support to this assumption comes from a recent paper demonstrating that microinjections of nefazodone, a serotonin antagonist, into the basolateral nucleus of amygdala reduce the aversive reactions induced by NMDA microinjections into the IC (Maisonnette et al, 2000).
The present results are in line with recent evidence obtained in this laboratory showing that latent inhibition, considered to be an animal model of schizophrenia, may be demonstrated using stimulation of neural circuits in the IC involved in the processing of acoustic information of aversive nature as negative reinforcement (Brandão et al, 1997). Also, our data clearly show that apomorphine inhibits the latent inhibition so induced and that these effects were antagonized by previous injections of chlorpromazine. Abnormal cortical areas are known to exist in schizophrenic patients and may account for the abnormal processing of auditory information consisting of auditory hallucinations and a decreased responsiveness to sounds (David et al, 1996). It has been claimed that a global control of the cortical function involved with sensory processing by the mesolimbic system needs to be considered in this field of study (Melo et al, 1997). These authors found that bilateral ablation of the auditory cortex enhances latent inhibition using a conditioned suppression response procedure. Taken together, the present results suggest that the IC supports the acquisition of conditioned responses, and that these paradigms may be useful for assessing the neurochemical substrates underlying the aversive effects of the stimulation of the IC.

The effects of apomorphine on latent inhibition remain the focus of some debate (Campeau and Davis, 1995). The differences reported among different experiments on the sensitivity of latent inhibition to apomorphine probably depend on the experimental conditions (Davis et al, 1990; Campeau and Davis, 1995) and the rat strain used (Swerdlow et al, 2000).

In summary, this work opens a new line of investigation relating neural substrates of aversion and fear within structures of the so-called brain aversion system at the midbrain tectum and DA-mediated mechanisms. Although more investigations are needed to clarify this field, our findings bring new evidence for a possible role of dopaminergic mechanisms in thesetting up of adaptive responses to threatening situations, which activate the neural circuits of the defensive behavior at the IC level.

\section{ACKNOWLEDGEMENTS}

This work was supported by FAPESP (Proc. 98/11187-2). AC Troncoso is the recipient of a scholarship from FAPESP. This work is part of a Brazil-France twinning convention (FAPESP/INSERM no. 98/11706-0).

\section{REFERENCES}

Abercrombie ED, Keefe KA, Di Frischia DF, Zigmond MJ (1989). Differential effects of stress on in vivo dopamine release in striatum, nucleus accumbens and medial frontal cortex. $J$ Neurochem 52: 1655-1658.

Adams JC (1979). Ascending projections to the inferior colliculus. $J$ Comp Neurol 183: 519-538.

Amano K, Tanikawa T, Iseki $H$, Kawabatake $H$, Notami $M$, Kawamura H, Kitamura K (1978). Single neuron analysis of the midbrain tectum. Rostral mesencephalic reticulotomy for pain relief. Appl Neurophysiol 41: 66-78. 
Anisman H, Zalcman S, Shanks N, Zucharko R (1991). Multisystem regulation of performance deficits induced by stressors: an animal model of depression. In: Boulton A, Baker GB, MartinIverson MT (eds). Animal Models in Psychiatry II. Human Press: Clifton NJ, pp 1-60.

Bandler R, De Paulis A, Vernes M (1985). Identification of midbrain neurones mediating defensive behaviour in the rat by microinjections of excitatory amino acids. Behav Brain Res 15: 107-109.

Bard P (1929). The central representation of the sympathetic system. Arch Neurol Psychiat 22: 230-246.

Bard P, Match MB (1951). In: Wolstenholme GEW, O'Connor CM (eds). The Neurobiological Basis of Behavior. The Ciba Foundation J\&A Churchill Ltd: pp 55-75.

Biggio G, Concas A, Corda MG, Giorgi O, Sanna E, Serra E (1990). GABAergic and dopaminergic transmission in the rat cerebral cortex: effect of stress, anxiolytic and anxiogenic drugs. Pharmacol Ther 48: 121-142.

Brandão ML, Aguiar JC, Graeff FG (1982). GABA mediation of the anti-aversive action of minor tranquilizers. Pharmacol Biochem Behav 16: 397-402.

Brandão ML, Anseloni VZ, Pandóssio JE, De Araújo JE, Castilho VM (1999). Neurochemical mechanisms of the defensive behavior in the dorsal midbrain. Neurosci Biobehav Rev 23 863-875.

Brandão ML, Cardoso SH, Melo LL, Motta V, Coimbra NC (1994). The neural substrate of defensive behavior in the midbrain tectum. Neurosci Biobehav Rev 18: 339-346.

Brandão ML, Coimbra NC, Osaki MY (2001). Changes in the auditory evoked potentials induced by fear-evoking stimulations. Physiol Behav 72: 365-372.

Brandão ML, Melo LL, Cardoso SH (1993). Mechanisms of defense in the inferior colliculus. Behav Brain Res 58: 49-55.

Brandão ML, Tomaz C, Coimbra NC, Bagri A (1988). Defense reaction induced by microinjection of bicuculline into the inferior colliculus. Physiol Behav 44: 361-365.

Brandão ML, Troncoso AC, Melo LL, Sandner G (1997). Active avoidance learning using brain stimulation applied to the inferior colliculus as negative reinforcement in rats: Evidence for latent inhibition. Neuropsychobiology 35: 30-35.

Brodal, P (1992). The Central Nervous System: Structure and Function. Oxford University Press: New York, USA

Campeau S, Davis M (1995). Prepulse inhibition of the acoustic startle reflex using visual and auditory prepulses: disruption by apomorphine. Psychopharmacology 117: 267-274.

Cardoso SH, Coimbra NC, Brandão ML (1994). Defensive reactions evoked by activation of NMDA receptors in distinct sites of the inferior colliculus. Behav Brain Res 63: 17-24.

Castilho VM, Avanzi V, Brandão ML (1999). Antinociception elicited by aversive stimulation of the inferior colliculus. Pharmacol Biochem Behav 62: 425-431.

Castilho VM, Brandão, ML (2001). Conditioned antinociception and freezing using electrical stimulation of the dorsal periaqueductal gray or inferior colliculus as unconditioned stimulus are differentially regulated by $5-\mathrm{HT}_{2 \mathrm{~A}}$ receptors in rats. Psychopharmacology 155: 154-162.

Cooper MH, Young PA (1976). Cortical projections to the inferior colliculus of the cat. Exp Neurol 51: 488-502.

Creese L, Hamblin MW, Leff SE, Sibley DR (1983). CNS dopamine receptors. In: Iversen LL, Iversen SD, Solomon $\mathrm{SH}$ (eds). Handbook of Psychopharmacology: Biochemical Studies of CNS Receptors. Plenun Press: New York, pp 81-138.

Cuadra G, Zurita A, Macedo CE, Molina VA, Brandão $\mathrm{ML}$ (2000). Electrical stimulation of the midbrain tectum enhances dopamine release in the frontal cortex. Brain Res Bull $\mathbf{5 2}$ 413-418.

David AS, Woodruff PWR, Howard R, Mellers JDC, Brammer M, Bullmore E et al (1996). Auditory hallucinations inhibit exogenous activation of auditory association cortex. Neuroreport 7: $932-936$

Davis M, Mansbach RS, Swerdlow NR, Campeau S, Braff DL, Geyer MA (1990). Apomorphine disrupts the inhibition of acoustic startle induced by weak prepulses in rats. Psychopharmacology 102: $1-4$.

Dean P, Redgrave P, Mitchell IJ (1988). Organization of efferent projections from superior colliculus to brainstem in rat: evidence for functional output channels. Prog Brain Res 75: 27-36.

Deutch AY, Tam SY, Roth RH (1985). Footshock and conditioned fear increase 3,4-dihydroxy-phenylacetic acid (DOPAC) in the ventral tegmental area but not substantia nigra. Brain Res 333 : 143-146.

Dunn LA, Atwater G, Kilts CD (1993). Effects of antipsychotic drugs on latent inhibition: sensitivity and specificity of an animal behavioral model of clinical drug action. Psychopharmacology 112: 315-323.

Espejo EF, Miñano FJ (1999). Prefrontocortical dopamine depletion induces antidepressant-like effects in rats and alters the profile of desipramine during Porsolt's test. Neuroscience 88: 609-615.

Fadda F, Argiolas A, Melis MR, Tissari AH, Onali PL, Gessa GL (1978). Stress-induced increase in 3,4-dihydroxyphenylacetic acid (DOPAC) levels in the cerebral cortex and in nucleus accumbens: reversal by diazepam. Life Sci 23: 2219-2224.

Faingold CL, Hoffmann WE, Caspary DM (1989). Effects of excitant aminoacids on acoustic responses of inferior colliculus neurons. Hear Res 40: 127-136.

Feenstra MGP, Botterblom MH (1996). Rapid sampling of extracellular dopamine in the rat prefrontal cortex during food consumption, handling and exposure to novelty. Brain Res 742: $17-24$.

Feenstra MGP, Botterblom MHA, Van Uum JFM (1995). Noveltyinduced increase in dopamine release in the rat prefrontal cortex in vivo : Inhibition by diazepam. Neurosci Lett 189: 81-84.

Furlan SM, Brandão ML (2001). Effects of systemic injections of dopaminergic agents on the habituation of rats submitted to an open field test. Neuropsychobiology 43: 83-90.

Fuster JM (1989). The Prefrontal Cortex: Anatomy, Physiology and Neuropsychology of the Frontal Lobe. Raven Press: New York.

Goldstein LE, Rasmusson AM, Bunney BS, Roth RH (1996). Role of the amygdala in the coordination of behavioral, neuroendocrine, and prefrontal cortical monoamine responses to psychological stress in the rat. J Neurosci 16: 4787-4798.

Graeff FG (1994). Neuroanatomy and neurotransmitter regulation of defensive behaviours and related emotions in mammal. Braz J Med Biol Res 27: 811-829.

Hoffman HS, Ison JAR (1980). Reflex modification in the domain of startle: I. Some empirical findings and their implications for how the nervous system processes sensory input. Psychol Rev 87: 175-189.

Hurdy YL, Suzuki M, Sedvall GC (2001). D1 and D2 dopamine receptor mRNA expression in whole hemisphere sections of the human brain. J Chem Neuroanat 22: 127-137.

LeDoux JE, Cicchetti P, Hagoraris A, Romanski LM (1990). The lateral amygdaloid nucleus: sensory interface of the amygdala in fear conditioning. J Neurosci 10: 1062-1069.

LeDoux JE, Sakagushi A, Reis DJ (1986). Subcortical efferent projections of the medial geniculate nucleus mediate emotional responses conditioned to acoustic stimuli. J Neurosci 4: 683-698.

Li Y, Evans MS, Faingold CL (1998). In vitro electrophysiology of neurons in subnuclei of rat inferior colliculus. Hear Res 121: $1-10$.

Lubow RE, Weiner I, Feldon J (1982). An animal model of attention. In: Spiegelstein MY, Levy A (eds). Behavioral Models and the Analysis of Drug Action. Elsevier: New York, pp 89-107. 
Makintosh NJ (1975). A theory of attention: variations in the associability of stimuli with reinforcement. Psychol Rev 82: 276298.

Maisonnette S, Huston JP, Brandao M, Schwarting RKW (1998). Behavioral asymmetries and neurochemical changes after unilateral lesions of tuberomammilary nucleus or substantia nigra. Exp Brain Res 120: 273-280.

Maisonnette SS, Kawasaki MC, Coimbra NC, Brandão ML (1996). Effects of lesions of amygdaloid nuclei and substantia nigra on aversive responses induced by electrical stimulation of the inferior colliculus. Brain Res Bull 40: 93-98.

Maisonnette S, Villela C, Carotti AP, Landeira Fernandez J (2000). Microinfusion of nefazodone into the basolateral nucleus of the amygdala enhances defensive behavior induced by NMDA stimulation of the inferior colliculus. Physiol Behav 70: 243-247.

Marseillan RF (1977). A solid state sine wave stimulator. Physiol Behav 19: 339-340.

Meininger V, Pol D, Derer P (1986). The inferior colliculus of the mouse. A nissl and golgi study. Neuroscience 17: 1159-1179.

Melo LL, Brandao ML (1995). Role of 5- $\mathrm{HT}_{1 \mathrm{~A}}$ and $5-\mathrm{HT}_{2}$ receptors in the aversion induced by electrical stimulation of the inferior colliculus. Pharmacol Biochem Behav 51: 317-321.

Melo LL, Brandão ML, Graeff FG, Sandner G (1997). Bilateral ablation of the auditory cortex in the rat alters conditioned emotional suppression to a sound as appraised through a latent inhibition study. Behav Brain Res 88: 59-65.

Melo LL, Cardoso SH, Brandão ML (1992). Antiaversive action of benzodiazepines on escape behavior induced by electrical stimulation of the inferior colliculus. Physiol Behav 51: 557-562.

Merzenich MM, Reid MD (1974). Representation of the cochlea within the inferior colliculus of the cat. Brain Res 77: 397-415.

Mitchell IJ, Dunn P, Redgrave P (1988). The projection from superior colliculus to cuneiform area in the rat. Exp Brain Res 72: 626-639.

Morrow BA, Elsworth JD, Rasmusson AM, Roth RH (1999). The role of mesofrontal dopamine neurons in the acquisition and expression of conditioned fear in the rat. Neuroscience 92: 553564.

Nashold BS, Wilson WP, Slaughter DG (1969). Sensations evoked by stimulation in the midbrain of man. J Neurosurg 1: 14-24.
Pandossio JE, Brandão ML (1999). Defensive reactions are counteracted by midazolam and muscimol and elicited by activation of glutamate receptors in the inferior colliculus of rats. Psychopharmacology 142: 360-368.

Pandossio JE, Molina VA, Brandão ML (2000). Prior electrical stimulation of the inferior colliculus sensitizes rats to the stress of the elevated plus-maze test. Behav Brain Res 109: 19-25.

Paxinos G, Watson P (1997). The Rat Brain in Stereotaxic Coordinates. 3nd edn. Academic Press: San Diego, CA.

Redgrave P, Dean P, Mitchell IJ, Odekunle A, Clark A (1988). The projection from superior colliculus to cuneiform area in the rat. Exp Brain Res 72: 611-625.

Rose JE, Greenwood DD, Goldberg JM, Hind JE (1963). Some discharge characteristics of single neurons in the inferior colliculus of the cat. I. Tonotopical organization, relation of spike counts to tonic intensity and firing patterns of single elements. J Neurophysiol 26: 294-320.

Sandner G, Canal NM, Brandao ML (2002). Effects of ketamine and apomorphine on inferior colliculus and caudal pontine reticular nucleus evoked potentials during prepulse inhibition of the startle reflex in rats. Behav Brain Res 128: 161-168.

Schmitt P, Carrive P, Discala G, Jenck F, Brandão M, Bagri A, Moreau JL, Sandner G (1986). A neuropharmacological study of the periventricular neural substrate involved in flight. Behav Brain Res 22: 181-190.

Skirboll LR, Grace AA, Bunney BS (1979). Dopamine auto and postsynaptic receptors: electrophysiological evidence for differential sensitivity to dopamine agonists. Science 206: 80-82.

Swerdlow NR, Martinez ZA, Hanlon FM, Platten A, Farid M, Auerbach P, Braff DL, Geyer MA (2000). Towards understanding the biology of a complex phenotype: rat strain and substrain differences in the sensorimotor gating-disruption effects of dopamine agonists. J Neurosci 20: 4325-4336.

Thierry AM, Tassin JP, Blanc G, Glowinski J (1976). Selective activation of the mesocortical DA system by stress. Nature (London) 263: 242-244.

Troncoso AC, Cirilo-Júnior G, Sandner G, Brandão ML (1998). Signaled two-way avoidance learning using electrical stimulation of the inferior colliculus as negative reinforcement: effects of visual and auditory cues as warning stimuli. Braz J Med Biol Res 31: 391-398. 